The Second Yearbook of Research and Statistical Methodology:

Books and Reviews, Edited by Oscar Krisen Buros. Pp. xxi +383 . (Highland Park, N.J. : The Gryphon Press, 1941.) 5 dollars.

$\mathrm{T}$ HE second issue of this Yearbook maintains the high standard of the first issue, covering the years 1933-38. Being greatly enlarged, it exhibits more fully the advantages of this original method of gathering in a single work of reference the critical and descriptive reviews which have appeared upon the literature in this branch of science. The excerpts presented in this Yearbook are longer and more informative than those in the first volume. The material covered has been extended, especially in mathematical economics, population studies and general histories of science. The appearance of the volume has been improved in many ways, including the use of larger type, and, although a work of this kind was particularly needed in respect of statistical methodology, the value and convenience of this venture should encourage the application of the same principles with respect to other branches of scientific literature.

Within the field with which the reviewer is most familiar, the excerpts from reviews have been made judiciously, and adequately represent the point of view and critical contributions of the reviewers, in addition to giving indirectly a good idea of the works noticed.

Since review notices are particularly liable to be scattered and inaccessible, it is a very great convenience to have them collected, reproduced, and well arranged.

R. A. F.

An Introductory Course in College Physics By Prof. Newton Henry Black. Revised edition. Pp. viii + 734. (New York : The Macmillan Company, 1941.) 3.75 dollars.

THIS is a revised edition of the author's "College 1 Physics" first published in 1935. The course is one whieh would suit most schools, though the author had in mind the needs of definite types of students. In this connexion, there is a slight bias towards physiology and medicine. Also it is pleasing to note that consideration is given to those students studying physics for the sheer joy of it, not with the view of taking any special examination; hence many applications to modern machinery and household devices are included.

Throughout the book emphasis is laid on fundamental laws and principles, and theories are introduced only in so far as they seem helpful in understanding significant facts. There is a good selection of numerical examples graded in difficulty, and the many labelled diagrams are very good; such diagrams are most helpful to students, and they save much descriptive matter.

The book runs to 734 pages, and a lot of ground is covered, but one feels that in some cases more should have been made of certain topies. For example, in view of the great importance of sound in modern applied physics, this section is rather thin; in a book covering the whole field of elementary physics, however, it is obviously impossible to treat all the subjects fully. The book is very well produced, and it is certainly a most useful addition to school physics books.

\section{Intermediate Electricity}

By Robert W. Hutchinson. Pp. viii + 628. (London : University Tutorial Press, Ltd., 1941.) 12s. 6d.

T THIS book is intended to replace the author's well-established "Text-book of Electricity and Magnetism", and it must be said at once that it is an exceedingly useful book.

The treatment is on modern lines, and a pleasing innovation is an introductory chapter on the modern theory of electricity and electrical phenomena; here the facts are stated simply, and they form a useful background for the student's future work. Another pleasing feature is the stress laid on the fact that magnetism itself is merely a phase of electricity, and it is refreshing, though unusual, to find the topics of terrestrial magnetism and atmospheric electricity discussed in the same chapter.

There are numerous fully worked examples; this is a good feature, especially for those students working alone. Emphasis is also rightly laid on the importance of units ; neglect of this work often leads to'confusion when students tackle numerical problems. The author does not set out to cater for any par. ticular examination, but the book more than covers the needs of those students preparing for the Intermediate Science, Higher School Certificate and Scholarship examinations. The mathematics in the book should be well within the compass of these students, though the average student may find the mathematics in the chapter on alternating current and varying currents rather formidable.

In spite of its rather high price, the book is excellent value, and if a student can afford it he will find it extremely helpful and useful.

Handbook of Economic Entomology for South India By Dr. T. V. Ramakrishna Ayyar. Pp. xix +528. (Madräs : Government Press, 1940.) 4.12 rupees.

K NOWLEDGE of South Indian insects has greatly Increased since the publication of 'T. B. Fletcher's book on the subject in 1914. This work is now out of print and there is a growing demand for its replacement by a more modern book. As a desideratum it has bəen filled by the appearance of Ramakrishna Ayyar's volume that is now before us. This writer is very well qualified for the task, having many papers and bulletins on South Indian economic entomology to his credit. The book is divided into two parts, and Part I deals with general aspects of the subject such as anatomy development and classification. Part II is in the main a conspectus of the chief injurious insects of South India and the best-known methods for combating them. The book is well printed and seems to be very free from errors, while its numerous illustrations add materially to its value. It should meet with a wide and speedy acceptance and fill a definite place in the literature of Indian economic entomology. 